\title{
Evaluation of p-wave Dispersion and Left Atrium Ejection Fraction in Patients with
}

\section{Cardioembolic Ischemic Stroke}

\author{
Avaliação da Dispersão da onda p e da Fração de Ejeção do Átrio Esquerdo em Pacientes com \\ Acidente Vascular Encefálico Isquêmico Cardioembólico \\ Evaluación de la Dispersión de onda p y Fracción de Eyección del Atrio Izquierdo en Pacientes con \\ Accidente Vascular Isquémico Cardioembólico
}

Received: 21/04/2021 | Reviewed: 28/04/2021 | Accept: 05/05/2021 | Published: 19/05/2021

\author{
Flávio Henrique Amaral Pires Véras \\ ORCID: https://orcid.org/0000-0001-7254-024X \\ University of State of Rio Grande do Norte, Brazil \\ E-mail: flaviohenrique@uern.br \\ Eduardo Pereira de Azevedo \\ ORCID: https://orcid.org/0000-0002-8630-6240 \\ University Potiguar, Brazil \\ E-mail: eduardo.azevedo@unp.br \\ Eudes Euler de Souza Lucena \\ ORCID: https://orcid.org/0000-0003-3119-7822 \\ University of State of Rio Grande do Norte, Brazil \\ E-mail: eudeseuler@hotmail.com \\ Francisco Irochima Pinheiro \\ ORCID: https://orcid.org/0000-0001-8879-3997 \\ University Potiguar, Brazil \\ E-mail: irochima@gmail.com \\ José Rodolfo Lopes de Paiva \\ ORCID: https://orcid.org/0000-0002-1554-3249 \\ University of State of Rio Grande do Norte, Brazil \\ E-mail: rodolfolopes@uern.br \\ Stephan Barisic Júnior \\ ORCID: https://orcid.org/0000-0001-7790-003X \\ University of State of Rio Grande do Norte, Brazil \\ E-mail: sbjr77@gmail.com \\ Fausto Pierdoná Guzen \\ ORCID: https://orcid.org/0000-0002-5458-7236 \\ University of State of Rio Grande do Norte, Brazil \\ E-mail: faustoguzen@uern.br
}

\begin{abstract}
Introduction: Studies show that p-wave dispersion and left atrial ejection fraction are predictors of cardiovascular events. Purpose: To verify the association of p-wave dispersion and left atrial ejection fraction with cardioembolic ischemic stroke. Methods: This is an observational, cross-sectional, case-control study with 61 patients, mean age of 65.6, with sinus rhythm ischemic stroke who underwent clinical evaluation with $\mathrm{CHA}_{2} \mathrm{DS}_{2}$-VASc score, electrocardiogram, echocardiogram and ultrasonography with Doppler of both carotid and vertebral arteries. The groups were divided into cardioembolic (cases) and non-cardioembolic (controls). The p-wave dispersion was obtained with a 12-lead electrocardiographic tracing at $50 \mathrm{~mm} / \mathrm{s}$ by subtracting the largest p-wave by the smallest one. Left atrial ejection fraction was obtained using the modified biplane Simpson method. This study was approved by the UERN Research Ethics Committee (\# 2,536,483). Results: Mean values for p-wave dispersion were $62.5 \mathrm{~ms}$ for cases and $49 \mathrm{~ms}$ for controls $(\mathrm{p}=0.025)$. For left atrial ejection fraction, the cases presented a mean of $42.9 \%$ and the controls a mean of $55.8 \%(\mathrm{p}=0.003)$. For the $\mathrm{CHA}_{2} \mathrm{DS}_{2}$-VASc score, the mean values were 3.6 and 3.1 for cases and controls, respectively $(\mathrm{p}=0.35)$. Cardiovascular risk factors showed similar distribution in both groups. Conclusion: p-wave dispersion and left atrial ejection fraction were associated with the cardioembolic patients with sinus rhythm that have gone through ischemic stroke.
\end{abstract}

Keywords: Stroke; p-wave; Atrial function.

\section{Resumo}

Introdução: Estudos demonstram que a dispersão da onda p e a fração de ejeção do átrio esquerdo são preditores de eventos cardiovasculares. Objetivos: Verificar a associação da dispersão da onda p e da fração de ejeção do átrio 
esquerdo com o acidente vascular isquêmico cardioembólico. Métodos: Trata-se de um estudo observacional, transversal e caso-controle, com 61 pacientes, idade média de 65,6 anos, com acidente vascular encefálico isquêmico em ritmo sinusal, submetidos à avaliação clínica, com determinação do escore de $\mathrm{CHA}_{2} \mathrm{DS}_{2}$-VASc, eletrocardiograma, ecocardiograma e ultrasonografia com Doppler de artérias carótidas e vertebrais. Os grupos foram alocados como cardioembólicos (casos) e não cardioembólicos (controles). A dispersão da onda p foi obtida com velocidade do traçado eletrocardiográfico de 12 derivações em $50 \mathrm{~mm} / \mathrm{s}$, através da subtração entre a maior e a menor onda p. A fração de ejeção do átrio esquerdo foi obtida através do método de Simpson biplanar modificado. Aprovado no comitê de ética e pesquisa da UERN com o número 2.536.483. Resultados: Os valores médios da dispersão da onda $\mathrm{p}$ foram de $62,5 \mathrm{~ms}$ para os casos e $49 \mathrm{~ms}$ para os controles ( $\mathrm{p}=0,025)$. Para fração de ejeção do átrio esquerdo os casos apresentaram média de $42,9 \%$ e os controles de $55,8 \%(\mathrm{p}=0,003)$. Para o escore de $\mathrm{CHA}_{2} \mathrm{DS}_{2}-\mathrm{VASc}_{\mathrm{OS}}$ valores médios foram de 3,6 e 3,1 para os casos e controles, respectivamente $(\mathrm{p}=0,35)$. Os fatores de risco cardiovascular mostraram distribuição semelhante nos 2 grupos. Conclusão: Nos pacientes em ritmo sinusal acometidos de acidente vascular encefálico isquêmico, a dispersão da onda p e a fração de ejeção do átrio esquerdo mostraram associação com o subtipo cardioembólico.

Palavras-chave: Acidente vascular encefálico; onda p; Função atrial.

\section{Resumen}

Introducción: Los estudios demuestran que la dispersión de la onda p y la fracción de eyección de la aurícula izquierda son predictores de eventos cardiovasculares. Objetivos: Verificar la asociación entre la dispersión de la onda p y la fracción de eyección de la aurícula izquierda con el Accidente cerebrovascular isquémico cardioembólico. Métodos: Se trata de un estudio observacional, transversal y de casos y controles, con 61 pacientes, edad media 65,6 años, con ictus isquémico en ritmo sinusal, sometidos a evaluación clínica, con determinación del score CHA2DS2VASc, electrocardiograma, ecocardiograma y Ecografía Doppler de arterias carótidas y vertebrales. Los grupos se asignaron como cardioembólicos (casos) y no cardioembólicos (controles). La dispersión de la onda p se obtuvo con la velocidad del trazado electrocardiográfico de 12 derivaciones a $50 \mathrm{~mm} / \mathrm{s}$, restando entre la onda p más grande y la más pequeña. La fracción de eyección de la aurícula izquierda se obtuvo mediante el método biplano de Simpson modificado. Aprobado por el comité de ética e investigación de la UERN con el número 2.536.483. Resultados: Los valores medios de la dispersión de la onda p fueron 62,5 ms para los casos y $49 \mathrm{~ms}$ para los controles $(\mathrm{p}=0,025)$. Para la fracción de eyección de la aurícula izquierda, los casos presentaron una media del 42,9\% y los controles, el 55,8\% ( $\mathrm{p}=0,003$ ). Para la puntuación CHA2DS2-VASc, los valores medios fueron 3,6 y 3,1 para los casos y controles, respectivamente $(\mathrm{p}=0,35)$. Los factores de riesgo cardiovascular mostraron una distribución similar en los 2 grupos. Conclusión: en pacientes con ritmo sinusal afectado por ictus isquémico, la dispersión de la onda p y la fracción de eyección auricular izquierda mostraron asociación con el subtipo cardioembólico.

Palabras clave: Accidente cerebrovascular isquémico; onda p; Función auricular.

\section{Introduction}

Since 1990 with the publication of the Global Burden of Disease study that cardiovascular disease has been recognized as the leading cause of death worldwide in both developed and underdeveloped countries (Murray, Lopez \& Jamison, 1994; Naghavi et al., 2015). At that time, it was estimated that coronary artery disease (CAD) and cerebrovascular disease (CVD) accounted for 5.7 and 4.6 million deaths worldwide, respectively. Epidemiological studies have shown that from 1990 to 2013 the incidence of CAD and CVD increased by 42 and 41\%, respectively. In fact, CAD and CVD account for $70 \%$ of deaths from cardiovascular diseases in low and middle-income countries (Naghavi et al., 2015).

Stroke, which is the leading cause of disability in the world, is characterized by a neurological deficit due to an acute focal injury of the central nervous system caused by a vascular event that includes cerebral infarction, cerebral hemorrhage and subarachnoid hemorrhage. Ischemic stroke is defined as an episode of neurological dysfunction caused by focal cerebral, medullary or retinal infarction. Infarction, in turn, should be diagnosed based on: 1) pathological, imaging or other objective evidence of cerebral, medullary or retinal ischemic injury with defined vascular distribution, or 2) clinical evidences of cerebral, medullary or retinal ischemic injury, based on symptoms lasting more than 24 hours or death, excluding other etiologies (Sacco et al., 2013).

Cardioembolic stroke corresponds to 14 to $30 \%$ of the cases, with the highest incidence observed in those over 85 years old. The heart embolus that leads to this subtype of stroke can be originated from 3 mechanisms: 1- thrombus formation by blood stasis in a dilated left heart chamber, 2- calcium detachment from a valve surface, and 3- thrombus formation by 
venous-arterial shunt. The emboli may be of varying sizes, but those originated from dilated cardiac chambers are often larger, leading to more severe and lethal ischemic stroke (Arboix \& Alió, 2010).

Cardioembolic stroke comprises events in more than one arterial territory. In general, cardiac emboli are large and usually leads to a single and extensive cerebral infarction around the basal nuclei or to multiple infarctions in the middle cerebral artery territory. With the aid of a computed tomography, images of bihemispheric cerebral infarction involving anterior and posterior circulation or multiple posterior infarcts can be used as strong indicators of cardioembolism (Hart, 1992; Caplan, 1995; Biller, Love, \& Schneck, 2008). However, magnetic resonance is more accurate than tomography for identifying ischemic stroke (Chalela et al., 2007).

In patients with atrial fibrillation, most protocols recommend assessing the risks for thromboembolic events, which is usually performed through $\mathrm{CHA}_{2} \mathrm{DS}_{2}$-VASc score. Such score is a sum of points attributed to cardiovascular pathologies and therefore, it considers the risk factors evaluated over time. Anticoagulation therapy is indicated for male patients with score $\geq 2$ and female patients with score $\geq 3$ (Magalhães et al., 2016; Wann et al., 2019). Thus, the aim of this study was to investigate whether there is any relationship between the p-wave dispersion and left atrial ejection fraction with the occurrence of ischemic stroke.

The primary objective is to assess the dispersion of the $\mathrm{p}$ wave and the left atrial ejection fraction in patients with ischemic stroke. Secondary objectives are defined cardiovascular risk factors, analysis of eletrocardiographic and ecocardiographic parameters and determine CHA2DS2-VASc score.

\section{Methodology}

This is an observational, cross-sectional and case-control study, previously approved by the Research Ethics Committee of UERN under No. 2,536,483, which followed the recommendations described in the resolutions 466/12 and 510/16 of the National Health Council. Data collection was performed from April/2018 to June/2019 and included patients older than 18 years old who were admitted to the Tarcísio Maia Regional Hospital of the city of Mossoró, state of Rio Grande do Norte - Brazil, with persistent neurological deficit for more than 24 hours, which underwent evaluation by a neurologist or neurosurgeon who recommended an exam of neuroimaging compatible with ischemic stroke (Hart, 1992; Caplan, 1995). Patients who presented atrial flutter or atrial fibrillation on the admission electrocardiogram or who refused to participate in the study were excluded. In addition, critically ill patients that required invasive mechanical ventilatory assistance were excluded as well.

Prior of being included in this study, patients or family members had to carefully read and sign an Informed Consent Form. The principal investigator would further explain to each participant about the research by adapting the technical language in a way that was easily understood, respecting the patient's cultural context, socioeconomic condition and autonomy.

For the initial evaluation, a questionnaire was used to obtain demographic information, educational level, race, comorbidities such as heart failure, acute myocardial infarction, systemic arterial hypertension, diabetes mellitus and transient ischemic vascular accident as well as lifestyle habits like smoking and physical inactivity.

The cases consisted of patients with cardioembolic stroke, whereas the controls comprised patients with noncardioembolic stroke. The neuroimaging exam was performed at the hospital using a SOMATON SCOPE 16 (SIEMENS ${ }^{\circledast}$ ) CT scanner and some patients required brain magnetic resonance imaging for supplementing the diagnostic. In addition, the $\mathrm{CHA}_{2} \mathrm{DS}_{2}$-VASc score was applied to each participant.

Twelve-lead electrocardiograms were performed within 3 days after admission with a standard amplitude of $1 \mathrm{~cm} / \mathrm{mV}$ and an increase in standard speed from $25 \mathrm{~mm} / \mathrm{s}$ to $50 \mathrm{~mm} / \mathrm{s}$ for better p-wave analysis. 
P-wave dispersion analysis was performed by a cardiologist by the analysis of all $\mathrm{p}$ waves of eletrocardiogram (Figure 1). The cardiologist was unaware of the other parameters evaluated in this study.

Figure 1: P-wave dispersion determination. P - longer p-wave; $\mathrm{P}$ - shorter p-wave; $\mathrm{d}$ - $\mathrm{p}$-wave dispersion.
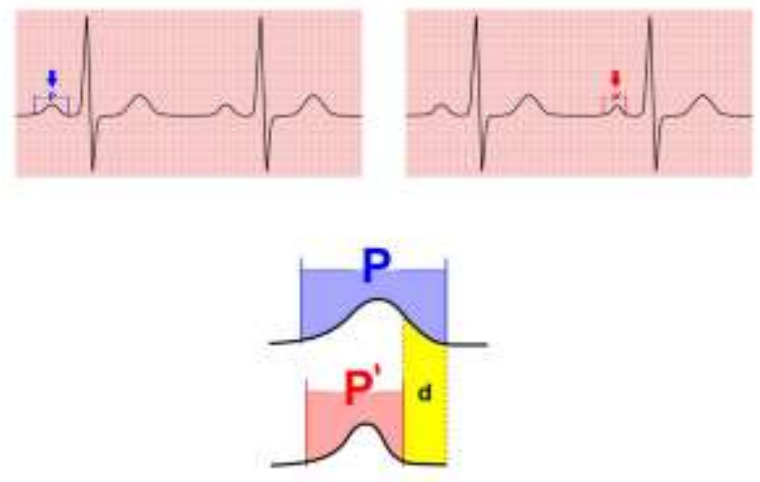

Source: Authors (2019).

P-wave dispersion (d) was obtained after the identification of difference between the largest and the smallest p-wave obtained in the electrocardiographic tracing. The beginning of the p-wave was defined at the junction between the isoelectric line at the beginning of the upward deflection and the end of the deflection. In other words, the beginning of the p-wave was considered as the junction point between the downward deflection and the isoelectric line (Dogan et al., 2012).

Examination was performed at the hospital using a 12-lead DIXTAL ${ }^{\circledR}$ electrocardiograph, where transthoracic echocardiograms were performed with standardized echocardiographic evaluations for the investigation of cardiopathies. Atrial ejection fraction (AEF) was obtained by the modified biplane Simpson method through orthogonal projections of apical 2- and 4-chambers, thus obtaining the diastolic and systolic volumes of the left atrium (Figure 2) (Lang et al., 2015).

Figure 2: Atrial ejection fraction (AEF), V2 - left atrial volume during systole and V1 - left atrial volume during diastole.
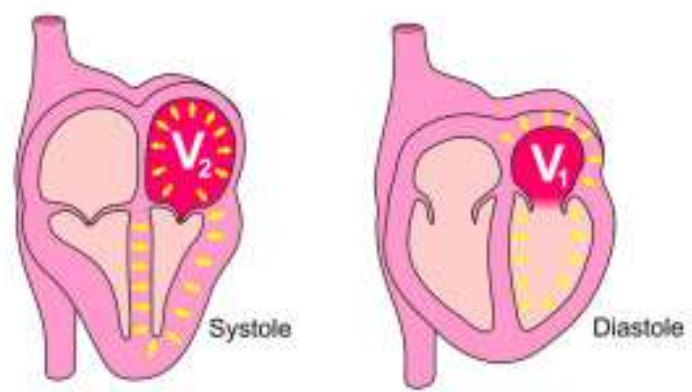

\section{$A E F=V_{2}-V_{1}$}

Source: Authors (2019).

Through the difference in volumes of the left atrium obtained by echocardiogram on the end of systole and diastole ventricular was determinate the AEF. 
For the investigation of carotid atheromatosis, Doppler ultrasonography of the carotid and vertebral arteries was performed at the same time as the echocardiogram with the patients being classified according to TOAST criteria (Adams Jr. et al., 1993). Ultrasound and echocardiography were performed if the patient were on sinus rhythm, at the hospital site within 5 days after the patient's admission using a Vivid $e\left(\mathrm{GE}^{\circledR}\right)$ device, which was operated by a qualified echocardiographist without knowing the other parameters evaluated in this study. Once the data was obtained, a neurologist evaluated the results and classified the ischemic stroke into one of the 5 subtypes following the TOAST criteria (Adams Jr. et al., 1993). These subtypes were grouped into cardioembolic and non-cardioembolic for comparison purposes.

Categorical variables were expressed as number and percentage, whereas continuous variables were expressed as means. Because they are non-uniformly distributed samples, the Mann-Whitney U-test was used for statistical analysis between the cardioembolic and non-cardioembolic groups. The independent variables p-wave dispersion, $\mathrm{AEF}$ and $\mathrm{CHA}_{2} \mathrm{DS}_{2}-$ VASc were compared with each other using Pearson and Spearman nonparametric tests. For evaluation of intra-examiner agreement for the variables p-wave dispersion and AEF, the simple Kappa coefficient with 10 random samples was performed. ROC curves were generated for the variables p-wave dispersion and AEF. Data were analyzed using IBM ${ }^{\circledR}$ SPSS software version 22.0. The level of rejection of the null hypothesis was set at 0.05 (Field, 2009).

\section{Results}

73 patients were initially included in this study, of whom 12 were excluded ( 7 by neuroimaging examination incompatible with ischemic stroke, 2 by non-interpretable electrocardiograms, 2 by evasion and 1 by inadequate echocardiographic window). The remaining 61 patients ( $54 \%$ male) had a mean age of 65.6 years. Regarding the subtypes, 26 (43\%) were classified as undetermined etiology, $15(24 \%)$ as atherosclerosis of the large arteries, $12(20 \%)$ as lacunar stroke and $8(13 \%)$ as cardioembolic (Figure 3$)$.

Figure 3: Stroke subtypes with their respective percentages of prevalence.

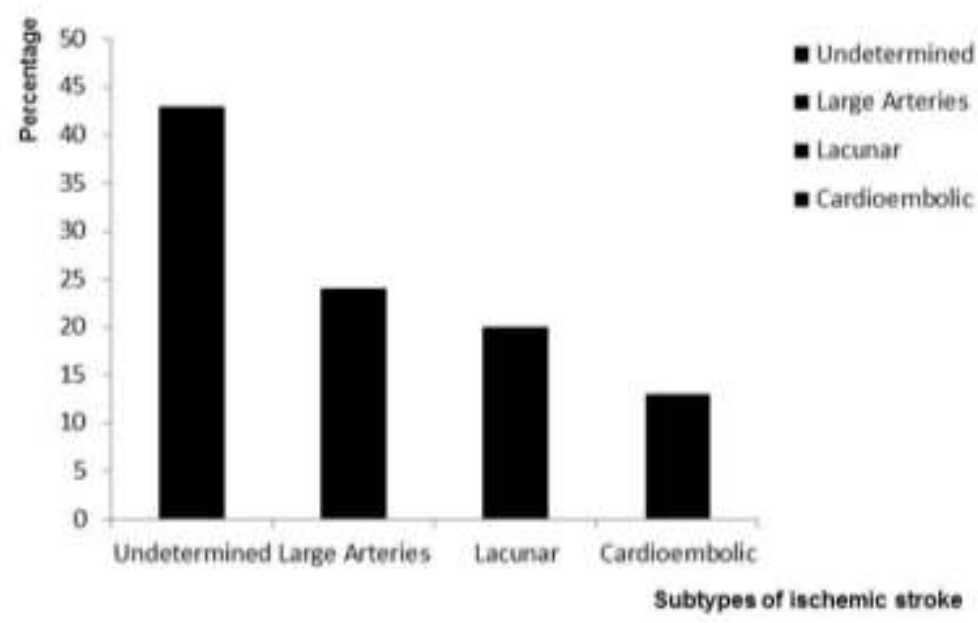

Source: Authors (2019).

For comparison purposes, 53 (87\%) were non-cardioembolic and 8 (13\%) were cardioembolic (Figure 4). 
Figure 4: Prevalence of cardioembolic and non-cardioembolic strokes among the patients in this study.

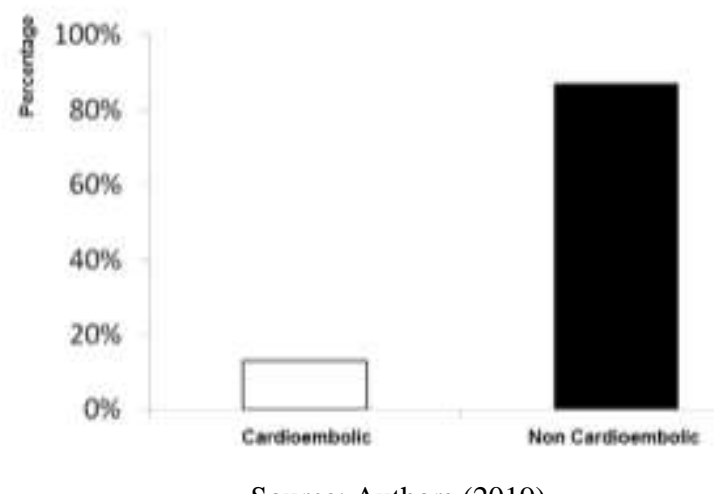

In the cardioembolic group, 4 patients had chronic coronary artery disease with segmental akinesia as evidenced by echocardiography, 2 had heart failure due to cardiomyopathy, 1 had significant rheumatic mitral stenosis and 1 had aortic mechanical prosthesis. Table 1 shows the distribution by age, sex, lifestyle and cardiovascular risk factors of both groups.

Table 1: Distribution by age, sex, lifestyle and cardiovascular risk factors.

\begin{tabular}{lccc}
\hline & Absolute values and percentages (\%) & P value \\
\hline Variables & $\begin{array}{c}\text { Cardioembolic } \\
(\mathrm{n}=8)\end{array}$ & $\begin{array}{c}\text { Non-cardioembolic } \\
(\mathrm{n}=53)\end{array}$ & 0.387 \\
\hline Age & 68,8 & 65.1 & 0.882 \\
Female & $4(50)$ & $24(45)$ & $0.014^{*}$ \\
Sedentary lifestyle & $5(62.5)$ & $49(92.4)$ & 0.207 \\
Tabagism & $2(25)$ & $26(49)$ & 0.846 \\
Hipertension & $5(62.5)$ & $35(66)$ & 0.682 \\
Diabetes mellitus & $3(37.5)$ & $24(45.3)$ & 0.786 \\
Dyslipidemia & $2(25)$ & $11(20.7)$ & 0.580 \\
Nephropathy & 0 & $2(3.7)$ & $0.025^{*}$ \\
Cardiac insufficiency & $2(25)$ & $2(3.7)$ & $0.020^{*}$ \\
Coronary artery disease & $5(62.5)$ & $12(22.6)$ & 0.580 \\
Transient ischemic & 0 & $2(3.7)$ & 0.211 \\
accident & & & \\
Stroke & 0 & $9(17)$ & \\
\hline
\end{tabular}

$*(\mathrm{p}<0,05)$. Source: Authors (2019).

On Table 1 it is observed significant estatistical difference on subtype Non-cardioembolic with more sedentary individuals and on subtype Cardiembolic there was more cases of Cardiac insufficiency and Coronary artery disease.

The $\mathrm{CHA}_{2} \mathrm{DS}_{2}$-VASc score showed similar values for both groups with no statistical difference, whereas $\mathrm{p}$-wave dispersion was higher and AEF was lower in cardioembolic patients compared with the non-cardioembolic ones, with $\mathrm{p}=$ 0.025 and 0.003 , respectively (Table 2 ).

Table 2: CHA2DS2-VASc, p-wave dispersion and AEF.

\begin{tabular}{lccc}
\hline & \multicolumn{2}{c}{ Medium values } & \\
\hline Variables & $\begin{array}{c}\text { Cardioembolic } \\
(\mathrm{n}=8)\end{array}$ & $\begin{array}{c}\text { Non-cardioembolic } \\
(\mathrm{n}=53)\end{array}$ & P value \\
\hline $\mathrm{CHA}_{2} \mathrm{DS}_{2}$-VASc & 3.6 & 3.1 & 0.350 \\
P-wave dispersion (ms) & 62.5 & 49 & $0.025^{*}$ \\
AEF $(\%)$ & 42.9 & 55.8 & $0.003^{*}$ \\
\hline
\end{tabular}

$A E F=$ Atrial Ejection Fraction. $*(\mathrm{p}<0,05)$. Source: Authors $(2019)$. 
ROC curves showed that the accuracy was 0.733 for $\mathrm{p}$-wave dispersion and 0,849 for AEF. According to Pearson and Spearman correlation coefficients there is no relationship between the independent variables analyzed in this study. The simple Kappa coefficient showed intra-examiner agreement of 1.0 for the variables p-wave dispersion and AEF.

\section{Discussion}

Despite the advances in the diagnosis of heart diseases, the incidence of stroke is still high. Although cardioembolic sources have been associated with patients with sinus rhythm, no study has demonstrated the benefits of anticoagulant or platelet anti-aggregating therapy (Beggs, Rorth, Gardner, \& McMurray, 2019). In some scenarios, the use of such therapy decreases the incidence of stroke, but increases the bleeding events. In cardiac patients without atrial fibrillation, the arrhythmia is detected in about $20 \%$ of the patients with 30-day monitoring after a stroke (Hohnloser et al., 2006) and 34.7\% with 2.5-year invasive monitoring (Healey et al., 2012). Expensive strategies with low availability are useful only for secondary prevention. Studies have recommend that patients with ischemic stroke in sinus rhythm have to be evaluated by $24 \mathrm{~h}$ Holter monitoring for detection of paroxysmal atrial fibrillation. This strategy has low sensitivity that ranges from 2.4 to $9.4 \%$ (Dogan et al., 2012).

In a meta-analysis of the main randomized controlled trials of patients with heart failure in sinus rhythm, a $37 \%$ relative risk reduction in stroke was observed in those using anticoagulation therapy compared with those using antiaggregation and placebo. In these studies, the incidence of stroke was low, therefore, it seems reasonable to assume that a large number of patients were on anticoagulation to have the chances of stroke reduced. Consequently, the potential benefit of stroke prevention was similar to the risk of bleeding events, even with the use of new oral anticoagulants (Beggs et al., 2019). In the COMMANDER HF clinical trial, the use of the new oral anticoagulant rivaroxaban reduced the risk of stroke from 1.6 to 1.1 events per 100 people/year, with an increase in the risk of bleeding events from 1.2 to 2.0 events per 100 people/year (Zannad et al., 2018). Thus, such reports show the importance of identifying risk markers and the use of severity scores to guide a more effective strategy for stroke prevention.

Knowing the cardiac substrate for thrombus formation suggests a better stratification of patients with higher risks of cardioembolic stroke. Cardiovascular risk factors, especially systemic arterial hypertension, diabetes mellitus and smoking, are known to be associated with cerebrovascular events. In the present study, the prevalence of risk factors as well as the $\mathrm{CHA}_{2} \mathrm{DS}_{2}$-VASc score were similar between the cardioembolic and non-cardioembolic groups. This score defines the indication for anticoagulation therapy in patients with atrial fibrillation, but to the best of our knowledge, there is no study involving patients with sinus rhythm. In this current study, a mean $\mathrm{CHA}_{2} \mathrm{DS}_{2}$-VASc score of 3.6 was found for patients with cardioembolic stroke, which would indicate anticoagulation therapy if atrial fibrillation was identified (Wann, 2019).

Even after excluding the patients with atrial fibrillation, $13 \%$ of the ischemic strokes had a cardioembolic etiology. Previous reports show a prevalence of 14 to $30 \%$, but these studies included patients with atrial fibrillation. In addition, emboli originated from dilated heart chambers are often larger, leading to more severe and sometimes more lethal stroke (Arboix et al., 2010). Considering the prevalence of stroke as 15 million cases/year, with about $70 \%$ being classified as ischemic and that atrial fibrillation is present in approximately $8.4 \%$ of the patients aged between 50 and 89 , there is an estimation of $1,250,340$ cases/year of cardioembolic stroke in patients with sinus rhythm around the world (Krishnamurthi et al., 2013; Wolf, Abbott, \& Kannel, 1991). Therefore, some questions can be raised regarding (1) whether there is any marker that can identify the highest risk patients, and (2) whether these patients, even at sinus rhythm, would benefit from a primary pre vention strategy.

High levels of p-wave dispersion reflect a prolongation of the intra and interatrial conduction time, as well as a heterogeneous conduction of the atrial stimulus. In fact, some studies show that p-wave dispersion is a risk factor for the development of atrial fibrillation, regardless of the presence of cardiovascular disease (Dilaveris \& Gialafos, 2001). In our 
study, a mean p-wave dispersion of $62.5 \mathrm{~ms}$ was obtained for patients with cardioembolic ischemic stroke. Dogan et al. (2012) suggest that a p-wave value greater than $57.5 \mathrm{~ms}$ is a predictor of paroxysmal atrial fibrillation with a sensitivity of $80 \%$, specificity of $73 \%$, positive predictive value of $74 \%$ and negative predictive value of $78 \%$. In another study, 74 patients with cardioembolic ischemic stroke showed a mean p-wave of $50.9 \mathrm{~ms}$ against $40.9 \mathrm{~ms}$ from 35 healthy patients (control group) (Acampa et al., 2015). The manual measurements showed greater intra and interobserver variability than digitized measurements (Dilaveris \& Gialafos, 2001). In our study, p-wave measurements were performed manually at twice the speed of electrocardiographic tracing to facilitate interpretation.

Atrial fibrillation is an independent cardioembolic risk factor for stroke, even though about $80 \%$ of the patients have sinus rhythm. In most cases, the emboligenic source is not so clear, even with transesophageal echocardiography, which leads to the search for an atrial anatomical substrate. The association of indexed volume of left atrium with ischemic stroke is controversial (Baturova et al., 2016; Yoon et al., 2013). On the other hand, the analysis of AEF, especially with longitudinal strain, shows a direct relationship with paroxysmal atrial fibrillation (Rasmussen et al., 2019). In fact, we found a reduction in AEF values in the cardioembolic group, which portrays a slowing in atrial emptying. In hypertensive patients, a higher probability of occurrence of paroxysmal atrial fibrillation with AEF $\leq 45 \%$ has been previously established (Tenekecioglu et al., 2014). The mean AEF obtained in our study for patients with cardioembolic stroke was $42.9 \%$. It is not a technique routinely used in echocardiographic examinations, but it is easy and straightforward as once the diastolic and systolic atrial volumes in the 2- and 4-chamber apical sections are determined, the software calculates AEF by the Simpson biplanar method (Lang et al., 2015).

Electrocardiographic and echocardiographic parameters show an association with cardioembolic stroke. At the analysis of the ROC curves, a greater correlation between AEF and ischemic stroke is observed in relation to p-wave dispersion. Due to the prevalence of risk factors in both groups, these are patients at high risk of cardiovascular events. The applicability and easy implementation of these methods brings us a future perspective for primary prevention studies.

\section{Conclusion}

Some heart diseases may be the etiology of stroke, even in patients with sinus rhythm. To date, studies have not shown any benefit from anticoagulant and platelet anti-aggregating therapy. The association of p-wave dispersion and AEF with cardioembolic ischemic stroke gives us a perspective for identifying patients with higher risks of cerebrovascular events. The results of our study encourage others researches with bigger number of patients and multicentric analysis.

\section{References}

Acampa, M., Guideri, F., Tassi, R., Buono, D. D., Celli, L., \& Mammarella, L. T., et al. (2015). P wave dispersion on cryptogenic stroke: A risk factor for cardioembolism? Internal Journal of Cardiology, 190, 202-204. 10.1016/j.ijcard.2015.04.185.

Adams Jr., H. P., Bendixen B. H., Kappelle, L. J., Biller, J., Love, B. B., Gordon, D. L., \& Marsh, E. E. (1993). Classification of subtype of acute ischemic stroke. Definitions for use in a multicenter clinical trial. TOAST. Trial of Org 10172 in Acute Stroke Treatment. Stroke, 24, 35-41. 10.1161/01.str.24.1.35.

Arboix, A., \& Alió, J. (2010). Cardioemboic Stroke: Clinical Features, Specific Cardiac Disorders and Prognosis. Current Cardiology Reviews, 6, 150-161. $10.2174 / 157340310791658730$.

Baturova, M. A., Sheldon, S. H., Carlson, J., Brady, P. A., Lin, G., Rabinstein, A. A., et al. (2016). Eletrocardiographic and Echocardiographic predictors of paroxysmal atril fibrillation detected after ischemic stroke. BMC Cardiovascular Disorders, 16(1), 209-217. 10.1186/s12872-016-0384-2.

Beggs, S. A. S., Rorth, R., Gardner, R. S., \& McMurray, J. J. V. (2019) Anticoagulation therapy in heart failure and sinus rhythm: a systematic review and meta-analysis. Heart, 105 (17), 1325-1334. 10.1136/heartjnl-2018-314381.

Biller, J., Love, B. B., \& Schneck, M. J. (2008). Vascular Diseases of the Nervous System - Ischemic Cerebrovascular Disease. In Bradley, W.G., Daroff, R.B., Fenichel, G.M., Jankovic, J. (Eds.) Neurology in Clinical Pratice. (pp. 1165-1212). London: Elsevier Health Sciences.

Caplan, L.R. (1995). Clinical diagnosis of brain embolism. Cerebrovasc Dis. 5, 79-88. https://doi.org/10.1159/000315468. 
Chalela, J.A., Kidwell, C. S., Nentwich, L. M., Luby, M., Butman, J. A., Demchuk, A. M., et al. (2007). Magnetic resonance imaging and computed tomography in emergency assessment of patients with suspected acute stroke: a prospective comparison. Lancet. 369 (9558), 293-298. 10.1016/S01406736(07)60151-2

Dilaveris, P. E., \& Gialafos, J. E. (2001). P-Wave Dispersion: A Novel Predictor of Paroxysmal Atrial Fibrillation. Ann Noninvasive Electocardiol,, 6 (2), 159165. 10.1111/j.1542-474x.2001.tb00101.x.

Dogan, U., Dogan, E.A., Tekinalp, M., Tokgoz, O.S., Aribas, A., Akilli, H., et al. (2012). P-wave Dispersion for Predicting Paroxysmal Atrial Fibrillation in Acute Ischemic Stroke. Internal Journal of Medical Sciences, 9 (1), 108-114. 10.7150/ijms.9.108.

Field, A. (2009). Descobrindo a Estatística usando o SPSS. (2a ed.). Artmed.

Hart, R. G. (1992). Cardiogenic embolism to the brain. Lancet, 339, 589- 94. 10.1016/0140-6736(92)90873-2.

Healey, J. S., Connolly, S. J., Gold, M. R., Israel, C. W., van Gelder, I. C., Capucci, A., et al. (2012). Subclinical Atrial Fibrillation and the Risk of Stroke. N Engl J Med. 366, 120-129. 10.1056/NEJMoa1105575.

Hohnloser, S. H., Capucci, A., Fain, E., Gold, M. R., van Gelder, I. C., Healey, J., et al. (2006). Asymptomatic atrial fibrillation and Stroke Evaluation in pacemaker patients and the atrial fibrillation Reduction atrial pacing Trial (ASSERT). American Heart Journal, 152, 442-447. 10.1016/j.ahj.2006.02.016.

January, C. T., Wann, L. S., Calkins, H., Chen, L.Y., Cigarroa, J. E., Cleveland Jr., J. C., et al. (2019). 2019 AHA/ACC/HRS Focused Update of the 2014 AHA/ ACC/HRS Guideline for the Management of Patients With Atrial Fibrillation A Report of the American College of Cardiology/American Heart Association Task Force on Clinical Practice Guidelines and the Heart Rhythm Society. Circulation. 2019; 140 (2), e125-e151. 10.1016/j.jacc.2019.01.011.

Krishnamurthi, R. V., Feigin, V. L., Forouzanfar, M. H., Mensah, G. A., Bennett, D. A., Moran, A. E., et al. (2013). Global and regional burden of first-ever ischaemic and haemorrhagic stroke during 1990-2010: findings from the Global Burden of Disease Study. Lancet Glob Health, 1 (5), e259-e281. 10.1016/S2214-109X(13)70089-5.

Lang, R. N., Badano, R. P., Mor-Avi, V., Afialo, J., Armstrong, A., Ernade, L., et al. (2015). Recommendations for Cardiac Chamber Quantification by Echocardiography in Adults: An Update from the American Society of Echocardiography and European Association of Cardiovascular Imaging. Journal of the American Society of Echocardiography, 28 (1), 1-53. 10.1016/j.echo.2014.10.003.

Magalhães, L. P., Figueiredo, M. J. O., Cintra, F. D., Saad, E. B., Kuniyoshi, R. R., Teixeira, R. A., et al. (2016). II Diretrizes Brasileiras de Fibrilação Atrial. Arq Bras Cardiol. 106 (4), 1-22. http://publicacoes.cardiol.br/2014/diretrizes/2016/02_II\%20DIRETRIZ_FIBRILACAO_ATRIAL.pdf.

Murray, C. J., Lopez, A. D., \& Jamison, D. T. (1994). The global burden of disease in 1990: summary results, sensitivity analysis and future directions. Bull World Health Organ, 72, 495-509. https://www.ncbi.nlm.nih.gov/pmc/articles/PMC2486716/.

Naghavi, M., Wang, H., Lozani, R., Davis, A., Liang, X., Zhou, M., et al. (2015). Global, regional, and national age-sex specific all-cause and cause-specific mortality for 240 causes of death, 1990-2013: a systematic analysis for the Global Burden of Disease Study 2013. Lancet, 2015; 385, 117-71.

10.1016/S0140-6736(14)61682-2.

Rasmussen, S. M. A., Olsen, F. J., Jǿrgensen, P. G., Fritz-Hansen, T., Jespersen, T., Gislason, G., et al. (2019). Utility of left atrial strain for predicting atrial fibrillation following ischemic stroke. Int J Cardiovasc Imaging, 35 (9), 1605-1613. 10.1007/s10554-019-01601-0.

Sacco, R. L., Kasner, S. E., Broderick, J. P., Caplan, L. R., Connors, J. J., Culebras, A., et al. (2013). American Heart Association Stroke Council, Council on Cardiovascular Surgery and Anesthesia, Council on Cardiovascular Radiology and Intervention, Council on Cardiovascular and Stroke Nursing, Council on Epidemiology and Prevention, Council on Peripheral Vascular Disease, Council on Nutrition, Physical Activity and Metabolism. An updated definition of stroke for the 21st century: a statement for healthcare professionals from the American Heart Association/American Stroke Association. Stroke, 44 (7), 20642089. 10.1161/STR.0b013e318296aeca.

Tenekecioglu, E., Agca, F. V., Ozluk, O. A., Karaagac, K., Demir, S., Peker, T., et al. (2014). Função Atrial Esquerda Prejudicada Associada com a Fibrilação Atrial Paroxística na Hipertensão. Arq Bras Cardiol. 102 (3), 253-262. https://doi.org/10.5935/abc.20140009.

Wolf, P. A., Abbott, R. D., Kannel, W. B. (1991). Atrial Fibrillation as an Independent Risk Factor for Stroke: The Framingham Study. Stroke, 22, 983-988. 10.1161/01.str.22.8.983

Yoon, J. H., Moon, J., Chung, H., Choi, E. Y., Kim, J. Y., Min, P., et al. (2013). Left atrial function assessedby Doppler echocardiography rather than left atrial volume predict recurrence in patients with paroxysmal atrial fibrillation. Clin Cardiol, 36 (4), 235-40. 10.1002/clc.22105.

Zannad, F., Anker, S.D., Byra, W. M., Cleland, J. G. F., Fu, M., Gheorghiade, M., et al. (2018). COMMANDER HF Investigators. Rivaroxaban in Patients with Heart Failure, Sinus Rhythm, and Coronary Disease. N Engl J Med, 379, 1332-1342. 10.1056/NEJMoa1808848. 